\title{
La configuración tipológica de "La abadesa preñada" de Berceo y su relación con la tradición apócrifa
}

\author{
The typological configuration of Berceo's "La abadesa preñada" \\ and its relation with the apocryphal tradition
}

\author{
Cinthia María Hamlin \\ SECRIT/Universidad de Buenos Aires \\ cinhamlin@gmail.com \\ ORCID iD: https://orcid.org/0000-0002-2194-0814
}

RESUMEN: Este trabajo profundiza la configuración tipológica del milagro XXI de Berceo a través del análisis de algunos elementos agregados respecto de la fuente latina que no fueron señalados por Boreland (1983) y que, sin embargo, acentúan la construcción de la Abadesa como "postfigura" o tipo (invertido e imperfecto) de María. Sostendremos también que Berceo construye la escena de la aparición y milagro mariano en relación estrecha a las escenas de la anunciación y la natividad, sirviéndose no sólo de la Vulgata, sino de una serie de motivos presentes en los Apócrifos de la natividad.

Palabras clave: Milagros, Berceo, abadesa preñada, tipología, tradición apócrifa.

ABSTRACT: In this study we will inquire into the typological configuration of Berceo's twentieth first miracle. We will analyse some added elements which are lacking in the Latin source and that have not been noticed by Boreland (1983). Such elements contribute to the configuration of the Abbess as a "postfigure" or as an inverted and imperfect type of Mary. Furthermore, we will argue that Berceo constructs the scene of the Marian apparition and miracle in close relation with the annunciation and nativity by using not only the Vulgate but also a series of motifs drawn from the apocryphal nativity tradition.

Keywords: Miracles, Berceo, pregnant abbess, typology, aprocryphal tradition. 
En su famoso estudio Figura, Auerbach (1998: 109) señala cómo la metodología de interpretación figural tiene una amplia difusión y "profunda resonancia" en la Edad Media, pues llega a influir no sólo en las obras teológicas y en los Padres de la Iglesia, sino también en el arte y, en particular, la literatura, como demuestran Los Milagros de Berceo. Antes de definir nuestro objetivo específico para el caso del milagro de "La abadesa preñada", comenzaremos repasando sucintamente de qué se trata la interpretación figural y a qué se debe su "profunda resonancia".

La tipología o interpretación figural puede ser definida como aquel mecanismo hermenéutico proveniente de la exégesis bíblica que interpreta un evento, persona o cosa del Antiguo Testamento en cuanto figura o tipo (figura vel typus) de una del Nuevo Testamento, el cual será su antitypus. Así, el sacrificio de Isaac por parte de Abraham será figura del sacrificio de Cristo. La clase de conexión que se realiza entre ambos es específicamente la de una simbolización alegórica: el primero no se reduce sólo a sí mismo sino que simboliza o preanuncia, siempre de manera imperfecta, al segundo, el cual a su vez incluye y consuma al primero ${ }^{1}$. Se trata, según señala Strubel (1975: 345 y sig.) de un "simbolismo de los hechos" o de los "referentes" - que son "a la fois choses et symbolisants" - en el cual, como aclara Auerbach (1998: 100), "nos la

\footnotetext{
${ }^{1}$ Véase al respecto el trabajo seminal de Auerbach (1998), especialmente pp. 99-100. Desde una perspectiva más teológica, son fundacionales también los trabajos de De Lubac (1959) y Woollcombe (1957). Resulta pertinente aclarar que en la Edad Media este procedimiento se conocía técnicamente como allegoria in factis distinto al otro tipo de alegoría, la in verbis o helenísica, en tanto que no se trata, según aclara Strubel (1975: 351), del típico procedimiento de significación alegórica en el que se dice una cosa para dar a entender otra, es decir, donde la relación de simbolización se da entre lo dicho y lo significado, sino que en este caso son las cosas o eventos a los que remiten esas palabras, los que a su vez, remitirán a otros. En la allegoria in factis, por tanto, la relación de simbolización alegórica se jugará entre los referentes. A su vez, la allegoria in factis propia de la exégesis bíblica implica, de acuerdo a la doctrina de los cuatro sentidos de la Escritura, un escalonamiento de sentidos alegóricos. En efecto, además del sentido literal o histórico, tenemos los tres sentidos espirituales (cuyo autor sería el mismo Dios) de los cuales el primero es el propiamente alegórico o tipológico (implica la consumación en el Nuevo Testamento de la figura representada por la littera), mientras que el segundo es el tropológico o moral (qué norma o comportamiento promueve en la vida del cristiano) y el tercero es el anagógico o escatológico (es decir, la consumación final de ese hecho luego del juicio final). Se trata de un escalonamiento y no de una pluralidad de sentidos, como aclara González (2010: 108), pues en ellos la veritas que encierra esa figura se va revelando en creciente plenitud, en los sucesivos escalones que representan la vida de Cristo, el alma de cada cristiano y la Gloria final. Así, "los tres sentidos espirituales no niegan, antes bien suponen y consuman el sentido histórico o literal, y el sentido histórico o literal a su vez exige el coronamiento de los tres espirituales" (González, 2010: 108-109). En términos generales, por tanto, el procedimiento exegético que relaciona uno y otro nivel es en sí tipológico: si el Éxodo de Israel es el typus y la Pascua y Resurrección de Cristo el antitypus (consumación en el Nuevo Testamento = sentido alegórico/ tipológico), ésta es a su vez el typus o figura (i.e. el preanuncio) de la resurrección final de los cristianos luego del juicio final (sentido anagógico).
} 
habemos con la historicidad real tanto de la cosa significante como de la cosa significada". En efecto, el procedimiento tipológico hunde sus raíces en la concepción propiamente cristiana de la historia según la cual Dios es el gran autor del Libro del mundo y dispone las cosas y los acontecimientos a modo de signo, confiriéndoles un sentido en relación a la encarnación y redención de Cristo. Este modo de concebir el acontecer histórico no se limita, sin embargo, a la historia comprendida entre la caída y la redención de Cristo (i. e. la historia de salvación narrada por los Evangelios), sino que abarcará toda la historia de la humanidad hasta el juicio final, de modo que cualquier evento en la vida de un cristiano puede contener elementos que imiten o reflejen algún aspecto de la historia de salvación. En resumidas cuentas, en la Edad Media la interpretación figural es no sólo un mecanismo hermenéutico aplicado a ciertos textos, sino más bien, un modo de interpretar y concebir el acontecer histórico (Auerbach, 1998: 109).

En el ámbito de la creación artística, específicamente la literaria, la técnica hermenéutica figural devino no sólo un dispositivo retórico que ofrecía a la obra de arte una serie de tópicos o motivos dicotómicos extraídos de los Evangelios (Eva/María, Edén/Paraíso, Isaac/Cristo, etc.) sino también un método de composición del relato, como se encarga también de demostrar Auerbach respecto del funcionamiento de personajes como Virgilio, Catón y Beatriz en la Divina Commedia (118-129)2. Asimismo Foster (1970: 18), en otro de los trabajos seminales al respecto, luego de aclarar que la "alegoría cristiana" está presente a partir del s. XIII mayoritariamente en obras de inspiración religiosa, señala: "an understanding of the role of figural interpretation in these works will contribute to the understanding of their structure in terms of the artist's own conception of the unity of human reality". De hecho, tanto Foster (1970) como antes Goode (1933) y luego Deyermond (1978) han probado cómo, en los Loores y el Sacrificio de la Misa, la técnica tipológica resulta la vertebradora de la estructura del relato.

En relación al texto que nos concierne aquí, los Milagros de Nuestra Seño$r a$, el uso del procedimiento tipológico ha sido ya profusamente trabajado en relación al "Prólogo alegórico" que inaugura la colección (cfr. Bayo, 2005;

\footnotetext{
${ }^{2}$ En efecto Dante, al elegir a los personajes que desempeñarán una función específica en la ficción de su viaje, lo hace de acuerdo a los acontecimientos o eventos reales de la vida de los mismos, los cuales son, de acuerdo a la mentalidad medieval umbra futurorum, es decir, sombra profética, figura, de lo que será su misma persona consumada en el más allá. Tomemos el ejemplo de Catón: "Catón es una figura, o más bien lo era aquel Catón terrenal que en Útica renunció a la vida por la libertad, mientras que el Catón que comparece en el purgatorio es la figura desvelada y consumada de aquel acontecimiento figural, puesto que la libertad política y terrenal por la que murió, no es más que una umbra futurorum: una prefiguración de aquella libertad cristiana cuya custodia le ha sido encomendada" (Auerbach, 1998; 117).
} 
Gerli, 1985; González, 2010; Orduna, 1967). En cuanto a los relatos milagrosos, sigue siendo de referencia obligatoria el célebre trabajo de Boreland (1983), quien parte de la premisa de que "certain of Berceo's Marian miracles recall biblical episodes, and that, whether subconsciuosly or deliberately, the Riojan poet interpreted and remodelled at least some of the narratives in his Latin source in a Typological fashion" (1983: 16). En este sentido, habría que aclarar que Berceo "remodela" la fuente latina de manera tipológica no sólo a nivel micro (introduciendo tanto comparaciones explícitas entre sus personajes y alguno de la Historia Sagrada, como elementos y/o acciones que, aunque más implícitos, los conectan inmediatamente a ellos) sino también a nivel macro, pues el patrón narrativo que siguen sus relatos, el de la caída y la redención (Gerli, 1985: 8), en la mayoría de los casos aparece reforzado gracias a un principio constructivo tipológico. Señalemos, a su vez, que Deyermond (1978: 99) y luego Boreland (1983: 15) han denominado a la modalidad específica de procedimiento figural que utiliza Berceo - aquel en la que un hecho del "aquí y ahora" representado en el relato remite a otro de la Historia de la Salvación- postfiguratio o "tipología retrospectiva", en tanto que la conexión entre los mismos es análoga a la que se establece en la Sagrada Escritura entre los hechos del Antiguo Testamento y el Nuevo Testamento, es decir, de imperfección versus consumación, aunque en dirección cronológicamente inversa.

Dicho todo esto, en este trabajo nos dispondremos a profundizar en la particular construcción tipológica que Berceo realiza del milagro XXI, "La abadesa preñada", con el objetivo de configurar al personaje como "postfigura" o tipo (invertido e imperfecto) de María. Con este fin, nos detendremos en algunos elementos agregados por Berceo en relación a la fuente latina que en el trabajo de Boreland no fueron tenidos en cuenta y que también tendrían una funcionalidad tipológica. Cabe aclarar que en este milagro se realiza, según ya advirtieron Boreland (1983: 21-22) y Diz (1995: 165), una doble construcción tipológica, pues en las primeras coplas la abadesa aparece relacionada con Eva, para luego configurarse, como ya señalamos, como postfigura de María. Nuestro interés aquí es centrarnos en esta segunda configuración tipológica, particularmente a partir del análisis de las variaciones que se introducen en relación a la concepción, el anuncio milagroso, el parto y el postparto ${ }^{3}$.

Asimismo, sostendremos la hipótesis de que Berceo construye la escena de la aparición y milagro mariano en relación estrecha a las escenas de la anunciación y de la natividad, sirviéndose no sólo de la Vulgata, sino de una serie de motivos presentes en las leyendas difundidas a partir de los apócrifos de la

\footnotetext{
${ }^{3}$ Más allá de los trabajos de Boreland y Diz recién citados, también se han dedicado al estudio de este relato milagroso, aunque desde una perspectiva diversa a la nuestra, los trabajos de Fidalgo (1995) y Benito-Vessels (2003).
} 
natividad, especialmente el Pseudo-Mateo, y también el De Nativitate Maria y el Liber de infantia Salvatoris.

Como ya se ha señalado profusamente, las narraciones apócrifas contaron con tal difusión y éxito en la Edad Media, en especial entre los siglos XI y XII, que entraron a formar parte, según Castro (2008: 209), del pensamiento "mitológico" cristiano medieval ${ }^{4}$. De toda esta prolífera tradición, de hecho, fueron el Pseudo-Mateo y el De nativitate los que según Santos Otero (2006: 118) más influjo tuvieron en la tradición popular y literaria de la Edad Media occidental, justamente por ser los más ortodoxos ${ }^{5}$, en cuanto que se difundieron a modo de contra-réplica de los apócrifos que transmitían doctrinas heréticas (Santos Otero, 2006: 5: Castro, 2008). Al respecto, agrega Marenzi (1968: 10):

Il materiale apocrifo, che ha incominciato a fiorire fin dal II secolo, e che ha trovato forse la sua origine dal desiderio di inserire la figura della Vergine in una realtà storica meno avara di dittagli e di notizie di quella offerta dai Sinottici, ha trovato larga diffusione e volgarizzazione nel Medioevo, divenendo la fonte remota o prossima dell'opera letteraria e dell'arte figurativa mariologica.

En efecto, en el desarrollo literario del tema mariano los relatos apócrifos de la natividad e infancia asumieron un papel de suma importancia (Brea, 2004-2005: 280), pues completaban los escasos datos biográficos presentes en los textos canónicos con narraciones maravillosas que, mientras defendían la ortodoxia - especialmente, la concepción y parto virginal de María-, resultaban realmente atractivas para saciar la curiosidad popular y estimular la piedad (Castro, 2008: 209). En relación a la producción mariana de Berceo, es en los Loores, compendio de la Historia de Salvación (García de la Concha, 1992: 65) en el que la Virgen tiene un papel preponderante, donde se han encontrado más motivos de procedencia apócrifa, la mayor parte relacionados con escenas de la anunciación y la natividad, aunque se han destacado asimismo posibles influencias en la Vida de Santo Domingo y en los Milagros ${ }^{6}$. En cuanto al relato que

4 Véanse al respecto los estudios de Santos Otero (2006), Bozoky (1984) y Marenzi (1968: 10) y, en el ámbito castellano, Brea (2004-2005) y Castro (2008: 207).

${ }^{5}$ En su magnífico estudio sobre los Evangelios Apócrifos Bozoky (1984: 430) refuerza la misma idea: "Les évangiles apocryphes de l'enfance de la Vierge et de celle de Jésus Christ se trouvent parmi les apocryphes les moins "hérétiques" et les plus influents sur la civilisation médiévale".

${ }^{6}$ Para el caso de los Loores tenemos primero el estudio de García de la Concha (1978), quien recaba varios motivos: los signos de Nacimiento (c. 29) y la estrella (c. 31), el suicidio de Herodes (c. 39), los nombres de los dos ladrones (c. 75) y el descenso a los infiernos (c. 102). Sin embargo, el crítico se encargaba de desestimarlos aduciendo que, dada la inclinación berceana por la objetividad escriturística, esas coplas serían una interpolación posterior proporcionada por la Legenda Aurea (Vorágine, 1982 [1267]). Deyermond (1981: 60) agrega a estos el motivo del suicidio del "segundo Herodes", Pilatos (cc. 121-122). En su edición, Salvador Miguel señala 
nos concierne, Boreland ha sido también pionera al insinuar una posible influencia apócrifa en relación a dos motivos en particular, pero desacierta al señalar cuál sería la fuente específica de la que proceden. Nuestra intención, por tanto, será revisar y profundizar sus postulados al respecto, recabando varios motivos apócrifos más que influyen especialmente en la escena del milagro y el posparto y que contribuyen a la configuración tipológica de la abadesa. Dado el carácter precursor que tiene para nuestro análisis el estudio de Boreland, en el primer breve apartado sintetizaremos los elementos tipológicos que allí se estudian, los cuales serán problematizados en los apartados subsiguientes.

\section{EL MILAGRO DE LA ABADESA Y SUS REMINISCENCIAS TIPOLÓGICAS IMPLÍCITAS}

Según los planteos de Boreland, habría entre el relato berceano de la abadesa y los relatos de la anunciación y la natividad una serie de "reminiscencias implícitas" - distintas de las "explícitas" presentes en la oración narrativa (cc. 518-527) - que sugerirían que Berceo interpretó la historia de la fuente latina en términos de una relación tipológica entre la Virgen y la abadesa (1983: 25). Así pues, el episodio que presenta más elementos que permitirían relacionar la figura de la abadesa preñada con la Virgen, y a esa escena con la de la anunciación, es el que se corresponde con el clímax del relato: la aparición de la Virgen y el posterior milagro. Como sabemos, el milagro sucede en su oratorio privado ("cerca de la su cámara do solié albergar / tenié un apartado, un apuesto logar: / era su oratorio en que solié orar"7, 514), en donde la abadesa le dirige a la Virgen su oración narrativa pidiéndole que la libere del embarazo. Luego de quedarse dormida, sobreviene la aparición:

$\begin{aligned} & \text { [A]parecióll la Madre del Rey de magestad, } \\ & \text { dos ángeles con ella de muy grand claridad. }\end{aligned}$
$\begin{aligned} & \text { Ovo pavor la dueña } \\ & \text { ca de tal vissión no mal espantada, }\end{aligned}$

todos estos motivos, mientras advierte que las deducciones de García de la Concha (1992: 876) no son suficientes para que las coplas respectivas sean espurias. En efecto, García López (2008: 55) recaba varios motivos y señala: "varias veces utiliza Berceo elementos de textos apócrifos, sea directamente o a través de lo que parece uso de una fuente cercana a la Legenda aurea". Díaz Tena (2010: 20) agregará también los objetos que le ofrecen los Reyes Magos a Jesús (c. 32). Para el caso de la Vida de Santo Domingo de Silos, Cea Gutiérrez (2001) destaca los motivos de la palma y la corona. En cuanto a los Milagros, Giles (2013: 285-288) ha señalado la relación del milagro de Ildefonso con el motivo de la Virgen confeccionando un tejido en el momento de la anunciación y en el milagro XVI Disalvo (2013: 160) ve una relación con el motivo del niño metido en un horno salvado por la Virgen (procedente del Evangelio árabe de la Infancia 29).

${ }^{7}$ Utilizaremos de aquí en más la edición de Fernando Baños (1997). Las cursivas, siempre nuestras. 

de la grand claridad fo mucho embargada,
pero de la su cuita fo mucho alleviada.
Díssoli la Gloriosa: "Aforzad, abadessa
bien estades comigo, non vos pongades quessa;
sepades que vos trayo mü̈ buena promessa, [...]
Non ayades nul miedo de caer en porfazo (529c-532a)

Finalmente, tenemos el milagro en sí:
Al sabor del solaz de la Virgo preciosa, non sintiendo la madre del dolor nulla cosa, nació la creatura, cosiella muy fermosa (533ac)

En este pasaje habría, según Boreland, tres reminiscencias tipológicas que acercan a las dos figuras. En primer lugar, el espacio donde recibe la aparición, ese oratorio que primero se designa como un "apartado" ( $i$. e e "aposento privado" según García Turza, 514b) ${ }^{8}$ cerca de la "cámara", recuerda el cubículo en el que María recibe la visitación del Ángel. Boreland señala que Berceo ya había hecho clara esa noción de que la Virgen estaba en una especie de cuarto apartado en los Loores ("ciella", habitación pequeña según Salvador Miguel, 1992: 874), y que el motivo se encuentra registrado tanto en el arte eclesial del período berceano, como en el Apócrifo Libro de Santiago (i. e. Protoevangelio de Santiago), donde María recibe la salutación, según Boreland (1983: 23), en su dormitorio. En segundo lugar, Boreland señala el "temor" de la dueña, y el posterior consuelo del visitante ("aforzad, abadessa") que remitirían, sigue la crítica, a la escena de Lc 1, 29-30, donde se relata la reacción de la Virgen frente al Ángel y cómo él la conforta. Y, finalmente, tendríamos el parto sin dolor, motivo que como señala muy bien Boreland, no deriva de los Evangelios canónicos, aunque Berceo ya lo utiliza en los Loores (22b) y en el Duelo (126ab). Al respecto la crítica no señala ninguna posible fuente, solo aclarará en nota que la doctrina del "parto sin dolor" de la Virgen es sostenida por la tradición cristiana ya desde la patrística (Boreland, 1983: 28).

Nos interesa detenernos brevemente en las fuentes señaladas para el primer motivo. Habría que destacar, por un lado, que en el Protoevangelio no aparece, en

\footnotetext{
${ }^{8}$ Aclaremos en este caso que en la rama latina el milagro sucedía en la "privata capella" de la abadesa. Desde nuestra perspectiva, la clave para entender la funcionalidad tipológica de este espacio es justamente el agregado del término "apartado" (514b) antes de designarlo específicamente como un oratorio (514c). Más allá de la aclaración de García Turza (2006: 421), la única acepción que ofrece el Diccionario Medieval Español de apartado en cuanto sustantivo dice: 'Aposento desviado del tráfago y servicio común de la casa y, en general, cada uno de los cuartos en que se divide una habitación, cámara' (Alonso, 1986: 331). Según el glosario de Bayo y Michael se trata de un 'aposento retirado'.
} 
realidad, ninguna referencia a un cuarto apartado: sólo se señala que la Virgen había ingresado en su casa - misma referencia ya presente implícitamente, según advierte Santos Otero (2006: 148, nota 67), en el Evangelio de Lucas "et ingressus angelus ad eam" (Lc 1, 28) $)^{9}$ - y que se encontraba hilando una púrpura (2006: 149). Por el otro, según aclara Santos Otero (2006: 126), este apócrifo griego no habría tenido influencia directa en la Edad Media occidental más allá de sus "redacciones o elaboraciones latinas: el Pseudo-Mateo y el De Nativitate Maria". En efecto, sólo en este último se encuentra una mención explícita del espacio donde sucede el anuncio en cuanto habitación o dormitorio, utilizando el término típico de la domus romana, cubiculum: "Denique ingressus ad eam, cubiculum quidem ubi manebat ingente ilumine perfudit" (De Nativitate 9,1$)^{10}$. Más allá de la confusión, es de destacar el aporte fundamental que ha hecho Boreland al advertir las posibles relaciones de este pasaje con la tradición apócrifa. La misma tendrá, como ya dijimos, un alcance mayor en la construcción de este milagro.

Señalemos, finalmente, que a estos motivos tipológicos enumerados por Boreland, cuya relación con la fuente latina, sus otras posibles fuentes y su funcionalidad específica ya problematizaremos, habría que agregarle otros elementos también ausentes de la rama latina: el embarazo maravilloso, la claridad, el motivo bíblico del noli timere y la "buena promessa", entre otros.

\section{Del PeCAdo, El EMBARgo y LA CLARIDAD}

Comencemos analizando de qué manera describe Berceo el pecado específico de la abadesa, el de la lujuria o ruptura de su voto a la virginidad y su posterior embarazo. En la introducción del relato, luego de detenerse en su bondad, caridad y en la honestidad con la que guiaba el convento, el narrador señala:

Pero la abadesa cadió una vegada,
fizo una locura que es mucho vedada,
pisó por su ventura yerba fuert enconada,
cuando bien se catido fallóse embargada. (507)

En la fuente latina, sin embargo, se describe el hecho de la siguiente manera:

Sociavit se livori earum insidiatoris antiqui semper infesta malignitas et eam, per quam sua sibi eripi vasa dolebat, a sanctitatis arce deicere modis

\footnotetext{
${ }^{9}$ Citamos de aquí en más la Biblia Vulgata por la edición de Colunga y Turrado (1951) de la Biblioteca de Autores Cristianos.

${ }^{10}$ Transcribimos la traducción de Santos Otero (2006: 249): "Y así, entrado que hubo hasta ella, inundó la estancia donde estaba de un fulgor extraordinario". De aquí en más todas las traducciones de los apócrifos corresponderán a su edición bilingüe. Las cursivas, siempre nuestras.
} 
omnibus festinabat. Invasit ergo celestem thesaurum latronis invidi versuta malicia et occulto iudicio Dei prevalens preciosum castitatis sigillum confregit, cunctis mundi opibus preferendum. Eius enim supplantata fraudibus prefata sanctimonialium mater, cum dapifero suo incesti crimen incurrit. Sed cum de occulto peccato diucius exultaret, disponente Deo qui de malis nostris suas laudes operatur, ingrato conceptu gravidata est (Baños Vallejo, 2011: 369-370) ${ }^{11}$.

El texto de Berceo, por tanto, omite la participación fundamental del diablo (Dutton, 1971: 174), que aparecía en la fuente no solo como incitador del pecado sino que se aludía a él como "ladrón" del tesoro de su santidad y como el culpable de romper su castidad. Asimismo se omite la mención del hermano de la orden con el que peca ("cum dapifero suo incesti crimen incurrit") para reemplazarlas por este "eufemismo" que utiliza uno de los motivos folclóricos de nacimiento maravilloso: pisar una yerba. Teniendo en cuenta la característica típica de la narración berceana, esa inmediatez que se funda en la abundancia de detalles concretos aunque se relacionen, en términos bajtinianos, con lo "inferior material y corporal" o específicamente con el acto sexual ${ }^{12}$, llama la atención esta particular construcción eufemística y la omisión del acto carnal concreto, que encuentra su explicación, sin embargo, en el interés de configurar a la abadesa en tanto tipo de María. Lo explicaremos en breve.

Ya en el episodio de la aparición encontramos otro motivo ausente de la fuente, el de la claridad, que se repite en dos ocasiones: la "gran claridad" que acompaña a los ángeles y esa gran claridad que la "embarga" en el momento de la visión. Respecto de la primera, recordemos el pasaje de la anunciación del apócrifo De Nativitate recién citado, donde se señala que al aparecérsele a María el ángel Gabriel "cubiculum (...) in genti lumine perfudit". A su vez, en la escena siguiente al nacimiento de Cristo en los Evangelios canónicos, el Ángel le anunciará a los pastores la buena nueva, apareciéndose de la siguiente

11 De aquí en más para los Miraculae Beate Marie Virginis utilizamos la transcripción de Gerli (1989). Para su traducción al castellano utilizaremos la versión de Avelina y Fátima Carrera de la Red (2000): “A la inquina de las monjas se unió la malicia siempre beligerante del antiguo urdidor de asechanzas que tenía prisa por derrocar, fuera como fuera, de la torre de la santidad a aquella de la que estaba dolido porque arrancaba de sus manos a las que él tenía por cosa suya. Así, pues, la astuta malicia del envidioso ladrón se abalanzó sobre el celestial tesoro y, valiéndose de los ocultos designios de Dios, rompió el precioso sello de su castidad, que merece más estima que todas las riquezas de este mundo. Porque la citada madre de las monjas, derribada por las artes del engañador, cometió un pecado de fornicación con su despensero. Mas, cuando ya llevaba bastante tiempo contenta porque su delito estaba oculto, por disposición de Dios, que de nuestras maldades saca alabanzas en su honor, quedó encinta con un embarazo no deseado".

12 Recordemos, por ejemplo, el caso del milagro de Guirald (VIII) en el que se señala explícitamente que, antes de partir en peregrinación a Santiago, "yogo con su amiga" (185b). Además, el texto aclara que al resucitar lo hace sin el miembro, pero con un agujerito para "verter su agua" (213b). 
manera: "et ecce angelus Domini stetit iuxta illos et claritas Dei circumfulsit illos" (Lc 2, 9). En la tradición apócrifa como en la canónica, por tanto, la claridad es el signo que acompaña el anuncio angélico.

Ahora bien, para comprender la funcionalidad de la segunda ocurrencia del término "claridad" ("de la gran claridad fo mucho embargada", 530c) en términos tipológicos, resulta necesario primero analizar cómo está funcionando en este relato el término "embargar" y sus derivados, en tanto que este término es, desde nuestro punto de vista, la clave que permite construir esta escena como postfigura de la anunciación. Encontramos en este relato, de hecho, otras tres ocurrencias del término "embargar", en las que Berceo explota el sentido múltiple que poseía este vocablo en el s. XIII: por un lado, el de 'embarazar' y, por el otro, el de 'abrumar' (más literalmente 'cargar', llenar de peso) ${ }^{13}$. En primer lugar, el verso ya citado en el que la abadesa pisa la "yerba enconada" y luego se advierte que "fallose embargada" (507). El embargada aquí funciona al mismo tiempo como embarazada y como afligida. Tanto la elisión de la figura masculina ya destacada, como el tópico folclórico del embarazo "sobrenatural" presente en el romancero y la poesía tradicional — según el cual la causa de estos embarazos mágicos podía ser desde yerbas malas hasta el viento (Devoto, 1974: 44; Garci-Gómez, 1989: 7-13) - son elementos que, en realidad, permiten acercar su figura a la de María, que también concibe "sobrenaturalmente" y sin varón. Las dos concepciones maravillosas, sin embargo, presentan signos opuestos: si la de María está fundada en la obediencia al designio divino, la de la abadesa en cambio se deriva de su desobediencia a la regla del celibato o de la virginidad monacal. A través de pequeños detalles como este Berceo va configurando a la abadesa como postfigura o tipo, invertido e imperfecto, de María.

En segundo lugar, luego de enviada la carta al obispo, se introduce la voz del narrador manejando la materia narrada: "digamos nós qué fizo la dueña embargada" (513c), en donde "embargada" se usa como sinónimo unívoco de "embarazada" y funciona, según Diz (1995: 166), a manera de epíteto caracterizador. Luego, en la oración narrativa a la Virgen que antecede (y desencadena) el milagro, la abadesa se refería a ella de la siguiente manera: "Madre por el amor de tu Fijo querido, / Fijo tan sin embargo, tan dulz e tan cumplido" (524ab). El "sin embargo" —que se referiría acá a 'perfecto' (Diz, 1995: 166), 'sin tacha' (Bayo y Michael, 2006: 242), 'sin defecto o imperfección' (García Turza, 1992: 696) - , sirve también para contraponer una y otra preñez.

Volviendo a la escena específica del hecho milagroso, en esa "claridad" de la que "fue mucho embargada", Berceo está explotando, desde nuestro punto

${ }^{13}$ En el Diccionario Medieval Español se señalan cuatro acepciones del término embargar durante el siglo XIII. En relación a nuestro trabajo nos interesa la primera ('embarazar', 'preocuparse') y la tercera ('abrumar', 'turbar') (Alonso, 1986: 988). 
de vista, el doble sentido de "embargar". En principio, esta claridad que la abruma es al mismo tiempo la que sustituye, según continúa Diz (1995: 167), el embargo físico de su cuerpo. Esta sustitución se acentúa en la estructura paralela de los dos segundos hemistiquios:

de la grand claridad fo mucho embargada,
pero de la su cuita fo mucho alleviada. $(530 \mathrm{~cd})$

En otras palabras, esta claridad milagrosa la "abruma" y al mismo tiempo la alivia, pues es el signo que preludia el milagro, en el cual será aliviada de la "carga" del embarazo ("se sintió delivre", 539a, "de tal cosa librada", 537d). A su vez, este verso en su sentido primero, como claridad que 'embaraza', remite claramente al momento "sobrenatural" en el que la Virgen concibe por obra del Espíritu Santo. De hecho, la relación entre luz y concepción está presente en toda la tradición apócrifa de la natividad (y llega, incluso, hasta Fra Angelico y su famosa Anunciación), como puede ejemplificarse con el pasaje correspondiente del Pseudo-Mateo $(9,1)$ : "Beata es, Maria, (...). Ecce veniet lux caelo ut habitet in te, et per te universo mundo resplendebit" 14 . Este verso, por tanto, mientras remite al momento específico en el que María concibe, contribuye a la construcción del personaje de la abadesa como su tipo (invertido). En efecto, si en la anunciación esa luz es el signo visible a través del cual se concibe, se da comienzo a un embarazo, en este caso será la luz el signo visible de la culminación del mismo. Luz como principio, en un caso, luz como fin en el otro. La escena de la anunciación, por tanto, se encuentra invertida.

\section{DEL ANUNCIO Y SUS MOTIVOS TÓPICOS}

Nos interesa retomar el segundo de los motivos tipológicos correspondientes a la escena de la anunciación que, según Boreland, Berceo agregaba en relación a la fuente latina: el temor ante la aparición. Como ya mencionamos, según esta crítica es el único de los tres motivos que remite a los Evangelios canónicos, específicamente al pasaje que reza así: "quae cum audisset, turbata est in sermone ejus, et cogitabat qualis esset ista salutatio" (Lc 2). Habría que destacar, en este caso, que el participio latino turbato/a no se relaciona con el miedo, sino con la confusión y la perplejidad ${ }^{15}$. La Virgen, según el texto en

14 "Dichosa eres, María [...]. He aquí que una luz del cielo vendrá para morar en ti, y, por tu medio iluminará a todo el mundo" (Santos Otero, 2006: 195).

15 De hecho, en el episodio del anuncio del nacimiento de Juan el Bautista a Zacarías, se señala también que quedó perplejo y, luego se agrega, que tuvo temor: "apparuit autem illi angelus Domini stans a dextris altaris incensi et Zaccharias turbatus est videns et timor inruit super eum" (Lc 1, 11-12). 
latín, "cuando lo oyó se quedó perpleja/confundida a causa de su discurso, y se preguntaba qué tipo de saludo era ese". En principio, por tanto, no es esta la fuente del motivo del temor que agregaría Berceo. A su vez, si volvemos al pasaje correspondiente de la rama latina, encontramos que, de hecho, el temor es un motivo recurrente, en principio en relación al futuro oprobio de la abadesa, pero también aparece insinuado en relación a la aparición. Veamos todo el pasaje:

(...) et intemerata Virgo Maria duobus comitantibus angelis clementer apparuit, et mestam misericorditer alloquens primo de tanta visione trepide et hesitanti quia misericordie Mater esset aperuit, et optati solatii verba subiunxit: "Audivi — ait - orationem tuam, vidi lacrimas tuas et me tibi a dulcissimo Filio meo penitentiam benigno susceptore noveris et peccati veniam et $a b$ infamie confusione quam times plenissimam liberationem impetrasse". Dixit, et duobus astantibus angelis, quemadmodum sibi videbatur, eam prolis onere quo gravabatur exonerarent precepit. Cuidam etiam heremite septimo miliario in vicino posito deferri, qui eius per septem annos gereret curam, mandavit. Quo facto liberatam pio monitu alloquens: "Ecce - ait- obprobio quod timebas erepta es, peccati laqueum deinceps cave (...)". His finitis visio disparuit et sanctimonialis evigilans omni quo prius cruciabatur honere carere se sensit (Baños Vallejo, 2011: 371) ${ }^{16}$.

Ante la visión, en este caso, la abadesa tiembla (trepide) y duda (hesitanti). Aunque, en principio, corroboramos que el temor no es un agregado de Berceo pues está insinuado en la fuente latina, desde nuestro punto de vista esto no iría en detrimento de la hipótesis de una construcción tipológica de la escena. Al contrario, sostenemos que Berceo por un lado agrega elementos tipológicos como los ya mencionados (la claridad, el embarazo sobrenatural y sin varón, el parto sin dolor), pero por otro también reelabora y acentúa otros elementos ya presentes en la rama latina de modo que, entrando en relación entre sí, remitan a los episodios de la natividad (sea los canónicos o los apócrifos), adquiriendo connotaciones tipológicas.

16 "[...] y la Virgen sin mancha, acompañada por dos ángeles, se le apareció clemente. Y hablándole con bondad a la triste, que al principio temblaba y dudaba de tal visión, le aclaró que era la Madre de misericordia y añadió estas palabras para darle el consuelo que pedía: He oído le dijo - tu oración, he visto tus lágrimas y te hago saber que he alcanzado para ti de mi Hijo, el cual benignamente acepta tu arrepentimiento, no sólo el perdón de tu pecado, sino también la liberación de la infamia y deshonra que estás temiendo. Así le habló y, según le pareció ver, dio orden a los ángeles que le acompañaban de que le exoneraran de la carga de la criatura de la que estaba embarazada y de que llevaran el niño a un ermitaño que vivía en las cercanías, a unas siete millas de allí, para que lo cuidara hasta los siete años. Hecho esto y dándole una piadosa reconvención a la que ya estaba libre, le dijo: Te has salvado de la deshonra que estabas temiendo, huye en adelante de los lazos del demonio [...]. Terminando de hablar, desapareció la visión y la monja despertó y notó que ya no tenía aquella carga que la atormentaba". 
En este sentido, habría que destacar que el motivo del temor de la Virgen ante la aparición (más el posterior "no temas") sí está presente en la tradición apócrifa, de la cual el Pseudo-Mateo $(9,2)$, como dijimos, fue el más difundido: “(...) ingressus est ad eam iuvenis, cuius pulchritudo non potuit enarrari. Quem videns Maria expavit et contremuit. Cui ille ait: «Noli timere Maria, invenisti gratiam apud Deum»"17. Si cotejamos el pasaje berceano con su fuente vemos, por un lado, que se explicita ese temor que el trementi sólo connotaba, incluso a través de una construcción pleonástica, que refuerza aún más la imagen: "ovo pavor la dueña e fo muy espantada" (530a). Notemos, a su vez, que se utiliza un término ("pavor") que posee la misma raíz presente en su equivalente latino del Pseudo-Mateo ("expaveo"). Por el otro lado, en el original latino el temor aparecía explícitamente dos veces, correspondientes cada una a los dos discursos que la Virgen le dirigía a la abadesa, pre y post milagro ("et ab infamie confusione quam times, plenissimam liberacionem impetrasse"; "Ecce — aitobprobio quod timebas erepta es (...)". En cada uno de ellos, a su vez, el verbo timere aparece en una proposición adjetiva que depende del objeto de la construcción verbal: el oprobio o infamia, de los que la Virgen le informa que su Hijo aceptó liberarla y, luego, del que ya ha sido liberada. Berceo reduce estos dos discursos de la Virgen a uno sólo previo al milagro y que adquirirá así, y gracias al agregado de la "buena promessa" (531c), ausente de la fuente latina, el carácter de anuncio ${ }^{18}$.

En efecto, la acción de "traer una buena promesa" ("sepades que vos trayo muÿ buena promessa”, 531c) entraría en estrecha relación con la acción específica que caracteriza el anuncio del Ángel en los otros dos episodios canónicos que protagoniza, el de Zacarías y el de los pastores (vid. infra): evangelizare, término del latín bíblico tardío que significa traer o dar una buena nueva ${ }^{19}$. A su vez, aunque este término no aparece exactamente en el discurso de Gabriel a María, la tradición lo entendió en estos términos, como demuestra San Victorinus: "quis itaque leges Dei doctus, quis plenus spiritu sancto, non respiciat

17 “[...] vino hacia ella un joven de belleza indescriptible. María al verlo quedó sobrecogida de miedo y se puso a temblar. Mas él le dijo: «no temas, María, porque has encontrado gracia ante los ojos de Dios»" (Santos Otero, 2006:194).

${ }^{18}$ El reacomodamiento de diferentes escenas es un recurso del cual Berceo ya se sirve, por ejemplo, en el milagro de San Ildefonso (Snow, 1982: 6 y Hamlin, 2015: 79 y sigs.).

${ }^{19}$ La definición de evangelizo, según el Dictionnaire Latin-Français des Auteres Chrétiens, es 'porter une bonne nouvelle' (Blaise, 1954: 317). Los episodios en cuestión rezan así: "Et Zacarias turbatus est videns, et timor irruit super eum. Ait autem ad illum ángelus: «Ne timeas Zacharia, quoniam exaudita est deprecatio tua: et uxor tua Elisabeth pariet tibi filium, et vocabis nomen eius Ioannem [...] Ego sum Gabriel, [...] et missus sum loqui ad te, et haec tibi evangelizare»" (Lc 1, 12-13. 19); “et ecce angelus Domini stetit iuxta illos et claritas Dei circumfulsit illos et timuerunt timore magno, et dixit illis angelus «nolite timere ecce enim evangelizo vobis gaudium magnum quod erit omni populo»" (Lc 2, 8). 
corde, ea die Gabrihel angelum Mariae uirgini euangelizasse, qua die draco Euam seduxit" (Victorin de Poetevio, 1997: 146).

Ahora bien, si analizamos el pasaje desde los mecanismos de traducción aplicados para el trasvase, podremos apreciar mejor los cambios y su funcionalidad. En principio, se omite el núcleo verbal de la acción de ambos casos, que se relacionaba con la liberación del oprobio: "liberationem impetrasse; obprobio erepta es". A su vez, ese verbo subordinado (quam times/quod timebas) al oprobio, pasa a convertirse en la locución verbal principal ("non ayades nul miedo") y la infamia u oprobio de los que dependía pasan ahora a ser su objeto "de caer en porfazo" (en términos estrictos, su complemento régimen), mecanismo que en el ámbito de los estudios de traducción se conoce como "transposición", $i$. e. cambio de estructura o categoría gramatical. Además, se realiza una doble "modulación" — cambio en la perspectiva o punto de vista—, pues la construcción verbal cambia su modo a imperativo y lo hace de manera antitética (negando una proposición afirmativa ${ }^{20}$. El resultado es la locución verbal "non ayades nul miedo" que queda a su vez focalizada, al ubicarse en el primer hemistiquio de la copla y estar separada de su objeto semántico ("de caer en porfazo") mediante la cesura. Esta locución, en el contexto de una aparición con las características ya analizadas, se relaciona directamente con el motivo bíblico del noli timere. Advirtamos, asimismo, que este motivo está presente no sólo en el anuncio del Ángel a María, así como se nos transmite tanto en la tradición canónica como en la apócrifa, sino que inaugura todos los anuncios del Ángel que forman parte de los episodios canónicos de la natividad. Por un lado, en el episodio inmediatamente anterior a la anunciación, el del anuncio del nacimiento de Juan el Bautista a Zacarías:

Et Zacarias turbatus est videns, et timor irruit super eum. Ait autem ad illum ángelus: "Ne timeas Zacharia, quoniam exaudita est deprecatio tua: et uxor tua Elisabeth pariet tibi filium, et vocabis nomen eius Ioannem [...] Ego sum Gabriel, [...] et missus sum loqui ad te, et haec tibi evangelizare (Lc 1, 1213. 19).

Por el otro, en el episodio inmediatamente posterior al nacimiento, el del anuncio de la llegada de Cristo a los pastores, donde leemos: "et ecce angelus Domini stetit iuxta illos et claritas Dei circumfulsit illos et timuerunt timore magno, et dixit illis angelus «nolite timere ecce enim evangelizo vobis gaudium magnum quod erit omni populo»" (Lc 2, 8).

Como vemos, en las distintas escenas protagonizadas por el Ángel que forman parte de los relatos de la natividad (incluidos los apócrifos) se repiten la

\footnotetext{
${ }^{20}$ Para los diversos procedimientos técnicos de traducción y sus clasificaciones seguimos a Vázquez-Ayora (1977). Los procedimientos de transposición y modulación se explican en las pp. $268-274$ y $293-313$
} 
misma serie de elementos que, por tanto, funcionaban como motivos distintivos de su anuncio, los cuales Berceo aprovecha en la construcción de su escena: la claridad, el temor, el "no temas" y el anuncio-promesa. En este sentido, habría que resaltar que en todos estos casos, igual que en el episodio de la anunciación a María del Pseudo-Mateo ya citado, el motivo del "no temas" aparece siempre antecedido por el del temor. Se entiende, pues, que Berceo se haya encargado de explicitarlo en contraste con su fuente y de acentuarlo mediante el pleonasmo. Como ya dijimos, Berceo reutiliza elementos presentes en la fuente pero reelaborándolos y enfatizándolos de modo que, al funcionar todos en conjunto (aparición y claridad +temor+ no tengas miedo+ anuncio) aplicados a la abadesa embarazada, remitan a la escena del anuncio del Ángel y acentúen las relaciones de similitud y oposición entre ella y la Virgen. En otras palabras, la escena de la anunciación no sólo está invertida en términos visuales o iconográficos, con esa imagen de la abadesa en un cuarto apartado recibiendo una visita sobrenatural que la inunda de luz mientras lleva, sin embargo, un embarazo muy avanzado, sino que el tipo de anuncio que recibe también es inverso. En efecto, la buena nueva no será la de un embarazo milagroso, sino la de la liberación milagrosa de su embarazo.

\section{Del PARTO Y LA MATERNIDAD}

Ahora bien, volviendo a la segunda ocurrencia del término "claridad" ("de la gran claridad fo mucho embargada", 530c), resulta interesante señalar que en las tradiciones apócrifas la luz es también el elemento esencial de la escena del parto de María, como podemos ver en Pseudo-Mateo y en De Liber infantia salvatori:

Ad ingressum vero Mariae coepit tota spelunca splendorem habere, (...) et quasi esset hora sexta diei, ita speluncam luz divina illustravit (PseudoMateo 13,2$)^{21}$.

Cum vero processit lux, adorauit eum que se vidit enixam, Erat autem ipse infans (solis modo) circumfulgens (...). Ego autem steti stupens (...) Intendebam enim in tantam claritatem luminis nati. Ipsa autem lux paulisper in se residens assimilavit se infanti (...) ut solens infanti nasci (De Liber infantia salvatori $73-74)^{22}$.

21 "Más en el momento mismo en que entró María, el recinto se inundó de resplandores (...). Aquella luz divina dejó la cueva como si fuera medio día" (Santos Otero, 2006: 202).

22 "[...]y en cuanto salió la luz, la doncella adoró a Aquel a quien reconoció haber ella misma alumbrado...yo por mi parte quedé llena de estupor...pues tenía fija mi vista en el intenso resplandor que despedía la luz que había nacido. Y esta luz fue de a poco condensando y tomando la forma de un niño, hasta que apareció un infante" (Santos Otero, 2006: 261). 
En términos teológicos, la importancia de la presencia de una luz extraordinaria en cuanto elemento sobrenatural que caracteriza el parto del Cristo se relaciona estrechamente con el otro elemento agregado por Berceo, el del parto sin dolor. Recordemos que Boreland señalaba al respecto que este no es un elemento presente en los Evangelios, aunque la doctrina del parto milagroso era la dominante entre los Padres de la Iglesia. Llama la atención, pues, que no mencione la importancia de este motivo en los textos apócrifos. De hecho, como ya mencionamos, el Pseudo-Mateo y el De nativitate fueron los dos apócrifos más difundidos, no sólo por ser los más "ortodoxos", sino sobre todo porque, según Santos Otero (2006: 118), tenían la "finalidad teológica" de "defender el honor de María, particularmente en lo que se refiere a su concepción y parto virginales", tradición teológica que estará en boga en época de Berceo (dentro de la cual él se inserta). En el Pseudo-Mateo (13, 3), luego de la escena de la gran claridad que impide que las dos parteras (Zelomi y Salomé) encontradas por San José ingresen a la cueva, una entra y, gritando, señala: "Nulla pollutio sanguinis facta est in nascente, nullus dolor in parturiente". El mismo pasaje se encuentra casi exactamente igual en el De liber infantia salvatoris (capítulo 70) ${ }^{23}$.

El parto sin dolor, de hecho, tiene varias significancias en el Medioevo. En el Génesis el parto con dolor es castigo impuesto a Eva y a sus hijas por el pecado ("Tantas haré tus fatigas cuantos sean tus embarazos: con dolor parirás los hijos", Gn 3, 16) y es a través de ese dolor que el pecado original se trasmite. La Virgen, en cambio, fue concebida sin pecado y, por tanto, pare sin dolor. El parto sin dolor es, pues, uno de los elementos centrales del contraste tipológico entre Eva y María: mientras sobre una pesa el pecado original y la maldición a todas las mujeres a través de los dolores del parto, la otra, a través del gozo de su parto, incorporará al mundo la redención (Bayo y Michael, 2006: 222) ${ }^{24}$. A su vez, según Santo Tomás (III, q.28 a.2; III, q35a.6), María debe parir sin dolor porque sigue siendo virgen después del parto. Así, para que se conserve la virginidad, en su parto no se habrían abierto las "vías", y es por eso que el Niño nace a través de una gran claridad, como se desarrolla en las escenas de los apócrifos citadas ${ }^{25}$.

23 "Ninguna polución de sangre en el nacido. Ningún dolor en la parturienta" (Santos Otero, 2006: 203). El pasaje del Liber (cap. 70) reza así: "Nulla polutio sanguinis facta est in nascente, nullus dolor in parturiente apparuit" ("ninguna mancha de sangre se ha producido en el recién nacido, ningún dolor se ha manifestado en la parturienta", Santos Otero, 2006: 259).

${ }^{24}$ En efecto, la relación Eva/María en cuanto tipo y antitipo fue tan difundida durante la Edad Media que llegó a constituirse en torno a ella la paranomasia anagramática Ave/Eva, Eva/Ave, que el mismo Berceo explota en su prólogo alegórico (véase Gerli,1985: 8).

${ }^{25}$ De hecho, una de las imágenes que utiliza la patrística para describir el parto virginal de María es la de que Cristo pasó como la luz por el cristal, véase el Nuevo Diccionario de Teología (Bargaglio, 1982: 975). 
Volviendo a nuestro texto, entonces, esta claridad que la "embarga" no sólo remite a la anunciación y concepción de Cristo sino también al momento específico del parto pues, como vimos, es esa claridad que la "embarga" (o aflige) la que al mismo tiempo la "alivia", es decir, le saca el peso del embarazo, por medio de un parto también sin dolor. En unos pocos versos, por tanto, se forma un sistema de connotaciones tipológicas que aluden simultáneamente a los episodios de la anunciación y la natividad de Cristo, así como se transmitían en las tradiciones canónicas y apócrifas. A su vez, en esta construcción, mientras presenta a la abadesa como posfigura de María (y, por tanto, a su niño como tipo de Cristo), se sugiere que el milagro de la Virgen borra el pecado de la abadesa (puesto que pare sin dolor), devolviéndole su estado de castidad/virginidad. Si, dijimos, en este milagro se realiza una doble construcción tipológica, primero relacionando a la abadesa con Eva y luego con María, este parto sin dolor que atraviesa el personaje representaría simbólicamente la victoria final de una sobre la otra en su propia historia de salvación ${ }^{26}$.

Asimismo, el nuevo estado de "castidad" de la abadesa sugerido por el texto será acentuado en las escenas posteriores en las que se describe su cuerpo sin rasgos de maternidad. Aclaremos que en este pasaje el texto latino es de por sí lacónico, mientras que Berceo agrega una cantidad de elementos que aportan una descripción muy realista de esta anulación de la maternidad que consiguió el milagro: apenas se despierta la dueña se palpa "por ventre, por costados e por cada ijada; / trobó su vientre llacio, la cinta muy delgada" (537bc) y luego recibe a los dos clérigos mandados por el obispo:

$\begin{aligned} & \text { Envió de sos clérigos } \\ & \text { que provassen la cosa }\end{aligned} \begin{aligned} & \text { en qui él más fiava } \\ & \text { de cuál guisa estaba; } \\ & \text { tolliéronli la saya, } \\ & \text { falláronla tan seca que li pesava, } \\ & \text { que tabla semejaba. }\end{aligned}$
$\begin{aligned} & \text { Non trovaron en ella } \\ & \text { nin leche nin batuda de preñedat, }\end{aligned}$

El texto berceano continúa muy cerca de su fuente latina: señala que los clérigos regresaron a narrar su hallazgo y que el obispo pensó que habían sido sobornados (558b) hasta que incorpora un breve discurso del obispo ausente de la fuente: "Disso: «Non vos lo quiero, tan aína creer / (...) yo quiero esta cosa por mis ojos veer»" (559ac) $)^{27}$.

\footnotetext{
${ }^{26}$ Este es un claro ejemplo de cómo en Berceo las relaciones tipológicas funcionan también a nivel macro a modo de principio constructivo del relato, reforzando el patrón de la caída y la redención (vid. supra p. 3).

${ }^{27}$ El pasaje de la fuente latina es el siguiente: "His finitis visio disparuit et sanctimonialis evigilans omni quo prius cruciabatur honere carere se sensit (...). Mittuntur post eam clerici duo
} 
Esta serie de variaciones, de hecho, también encuentra su correlato en los textos apócrifos, especialmente en Pseudo-Mateo y el episodio de las comadronas, uno de los más difundidos a pesar de la oposición de San Jerónimo ${ }^{28}$, pues estos personajes son los que constatan la virginidad in partu et post partum. Apenas la Virgen pare a través de esa gran luz, entra a la cueva la primera de las parteras que consigue José, Zelomi, quien le pide permiso a María para palparla y luego exclama gritando:

Domine, domine magne, miserere. Nunquam hoc auditum est nec in suspicione habitum, ut mamillae plenae sint lacte et natus masculus matrem suam virginem ostendat. Nulla pollutio sanguinis facta est in nascente, nullus dolor in parturiente (Pseudo-Mateo 13, 3-4).

Enseguida la segunda partera, Salomé, escucha: "Audiens hanc vocem alia obstetrix Salome, dixit «Quod ego audio non credam nisi forte ipsa probavero». Et ingressa Salome ad Mariam, dixit: «Permitte me ut palpem te et probem utrum verum dixerit Zelomi»»"(Pseudo-Mateo 13, 3-4) ${ }^{29}$. Encontramos aquí el motivo del parto sin dolor ya citado, el de la incredulidad del segundo testigo del milagro y, más importante aún, la referencia explícita a la leche de la Virgen como prueba de su maternidad ${ }^{30}$. Además, constatamos que el término lati-

pontificali iussu qui divulgatum de ea crimen explorent. Accedunt, attendunt et nullum in ea uteri prole fecundi signum deprehendunt. Mulieris innocenciam presuli renunciant, sed illos ipse pecunia corruptos existimans per semetipsum rei veritatem curiosius explorat. Itaque nullum in ea criminis obiecti vestigium cernens, eius ad pedes corruit, veniam de illatis iniuriis exposcit" ("Terminando de hablar, desapareció la visión y la monja despertó y notó que ya no tenía aquella carga que la atormentaba (...). Por orden del obispo son enviados dos clérigos para que investiguen el delito que se ha divulgado sobre ella. Se acercan, la auscultan, pero no encuentran indicio alguno de que su vientre vaya a tener una criatura. Vuelven al obispo con la noticia de que esa mujer es inocente, pero él, pensando que les ha sobornado a base de dinero, investiga por sí mismo con más rigor la verdad del caso, y no encontrando en ella rastro alguno del delito imputado, cae a sus pies y le pide perdón por las injurias proferidas contra ella").

${ }^{28}$ San Jerónimo se opone abiertamente, señalando que María fue parturienta y obstétrica al mismo tiempo, en De Perpetua Virginitate Mariae, Adv. Helvid 10, PL 23, 202. Como señala Santos Otero (2006: 202-203), la oposición de San Jerónimo a la difusión de esta leyenda no tuvo éxito.

${ }^{29}$ Aquí la traducción de todo el pasaje de Santos Otero (2006: 203): “«Señor misericordia! Jamás se ha oído ni ha podido caber en cabeza humana que estén henchidos los pechos de leche y que haya nacido un infante dejando virgen a su madre. Ninguna polución de sangre en el nacido. Ningún dolor en la parturienta» (...) La otra comadrona, llamada Salomé, al oir esto dijo «No creeré jamás lo que oigo, si yo misma en persona no lo compruebo». Y se acercó a María diciéndole: «Déjame que te palpe para ver si es verdad lo que acaba de decir Zelomi»".

${ }^{30}$ La posible influencia en la escena de la inspección de la abadesa de un texto apócrifo ya había sido insinuada, muy fugazmente, por Boreland (1983: 24 y 28, nota 32), quien lo remitía al Pseudo-Santiago, basándose en el único elemento repetido: la incredulidad de Salomé. Como ya mencionamos, este apócrifo no habría tenido influencia en la Edad Media, más allá de sus reelaboraciones latinas. 
no que se utiliza, tanto para referir a la acción del examen físico, como el de comprobar la verdad, es el mismo en este pasaje (provare) que el que utiliza Berceo una y otra vez, con las mismas dos acepciones, en el pasaje citado (555b) y en tres ocasiones más (553b y 560d). En el original latino, en cambio, para referir a la comprobación del crimen se utilizaba el término explorare $\mathrm{y}$, para la acción del examen físico, attendere (vid. nota 27).

Asimismo, la función del clérigo y el obispo será la misma que la de las dos parteras. Aunque, en principio, el objetivo de los personajes es comprobar el crimen, esto es, si la abadesa está o estuvo embarazada, lo cierto es que su escena funciona de la misma manera que en los apócrifos: para constatar el hecho milagroso de su virginidad "post-parto". La abadesa, entonces, también en esta escena postfigura a María, pero lo hace de manera imperfecta e invertida pues, al no presentar signos de embarazo, ni de leche, aparece desprovista de su maternidad. Por tanto el milagro, que en ese parto sin dolor borra el pecado, opera volviéndola a su estado primigenio: no será virgen y madre, como María, sino que será sólo virgen. El motivo de la leche, cuya ausencia en la abadesa Berceo recalca, es el elemento que en relación al pasaje apócrifo permite aquí contraponer una y otra figura, contraposición que también se insinúa de manera intratextual, pues la leche aparece en otros milagros como atributo específico de la maternidad de la Virgen ("Yo só Sancta María / madre de Jesu Cristo, que mamó leche mía", 109b y "[Dios] de cuya lege quiso con su boca mamar", 75d ${ }^{31}$. En efecto, en este milagro es la Virgen la que asume la función de madre y manda "educar" al niño por un ermitaño.

Esta construcción, de hecho, permite acentuar las características tipológicas que va a asumir el pequeño bebé en relación a Cristo, parido también sin dolor (y por tanto sin pecado) en una escena que presenta ecos de la natividad. A esto se le suma la referencia específica al modo en el que los clérigos lo encuentran cuando van a corroborar el milagro: "embuelto en un paño" (568d) de la misma manera en la cual, como ya señaló Boreland, el ángel del Señor avisa a los pastores que encontrarán a Cristo (Lc 2,12). Este epílogo en el que Berceo se detiene mucho más que la fuente en la figura del niño, para culminar señalando cómo se convierte en obispo, demuestra la función ideológica que hilvana toda la construcción tipológica de este relato: legitimar la autoridad eclesiástica. En efecto, esta intervención concreta de la Virgen al inicio de la educación y de la carrera del niño-obispo narrativiza y escenifica - igual que en el milagro del "Nuevo obispo" (XIII), en el cual el obispo es elegido direc-

${ }^{31} \mathrm{La}$ "Virgen de la leche" es, de hecho, una figura recurrente en el arte mariológico, tanto el iconográfico como en los relatos milagrosos, como ejemplifica no sólo Berceo sino numerosos relatos de las Cantigas de Santa María. Para el caso de los Milagros véase Chaves y Labarta (1978: 98) y para las Cantigas, Domínguez Rodríguez (1984: 35-38). 
tamente por la Virgen - la concepción teológica según la cual los religiosos son elegidos para ocupar ciertos cargos jerárquicos por la misma divinidad y que su autoridad, por tanto, emana directamente de ella. En este caso, su autoridad está doblemente avalada, pues el relato lo presenta como una postfigura de Cristo. De igual manera opera ideológicamente la construcción tipológica del personaje de la abadesa. En el plano de lo narrado, mientras el pecado de la abadesa ofrece una excusa a las monjas para deshacerse de su figura autoritaria (510ab) e impone un cuestionamiento en el obispo acerca de su idoneidad para ejercer su cargo (tanto que será echada del convento), el milagro tiene la función no sólo de reponer el orden y borrar el pecado, sino también, gracias a esa intervención concreta de la Virgen, de reafirmar el origen divino de su idoneidad en cuanto abadesa. En el plano retórico, esta reafirmación de la autoridad eclesiástica incluso en el pecado se acentúa, justamente, al presentar a la figura de la abadesa redimida como una postfigura - figura invertida e imperfecta- de la Virgen.

\section{LA CONFIGURACIÓN TIPOLÓGICA BERCEANA: ENTRE LA TEOLOGÍA Y LA TRA- DICIÓN POPULAR}

A modo de conclusión, primero nos gustaría detenernos en unas reflexiones generales. Mencionamos en la introducción cómo, según Auerbach (1998: 109), la interpretación figural se volvió en la Edad Media un modo de interpretar y concebir el acontecer histórico — que abarca toda la historia de la humanidad, no sólo la comprendida entre la caída y la redención de Cristo - de modo que cualquier evento de la vida de un cristiano podía contener elementos que imitaran o reflejaran la historia de salvación. Los Milagros de Berceo son una acabada muestra de cómo esta concepción cultural determina también la creación artística y literaria, no sólo por la cantidad de reminiscencias o motivos tipológicos de los que se sirve, sino sobre todo porque sus relatos se construyen siguiendo el patrón narrativo de la caída y la redención. El caso del relato de la abadesa es uno de los más paradigmáticos, puesto que el patrón caída-redención aparece reforzado gracias a una doble construcción tipológica que relaciona la figura de la abadesa primero con Eva y luego, más explícita y acabadamente según hemos demostrado, con María. En otras palabras, la detallada y minuciosa construcción de la abadesa como postfigura de María, a partir de la intervención milagrosa de la Virgen que borra el pecado por medio de un parto sin dolor, representa la victoria final de María sobre Eva en su propia historia de salvación. De la misma manera cada milagro, a su manera y en mayor o menor medida, ejemplificará cómo la vida de cualquier cristiano puede reproducir aspectos de la historia de salvación, aunque siempre de manera incompleta o im- 
perfecta, puesto que en el tiempo post-Cristo la consumación total sólo se repetirá en el más allá. En efecto, el concepto de post-figuración o tipología retrospectiva resulta el más apropiado y preciso para definir el tipo de construcción tipológica que realiza Berceo, en el cual los eventos del aquí y ahora del relato, eventos post-redención de Cristo, remiten y se relacionan con la historia de salvación, pero lo hacen, sin embargo, siguiendo el orden temporal opuesto al de la tipología bíblica. Así, si los eventos del Antiguo Testamento representan un preanuncio o prefiguración imperfecta (y muchas veces inversa) del evento que se consumará en el Nuevo Testamento, los eventos o personas de los relatos de Berceo son postfiguración imperfecta y, en el caso de la abadesa también inversa, de los eventos que ya se habían consumado en el Nuevo Testamento: el tipo de relación es la misma, aunque en dirección cronológicamente inversa. Resulta menester aclarar, pues, que Berceo al construir a la abadesa como postfigura invertida de María está siguiendo, de hecho, el mismo principio constructivo bíblico según el cual los personajes que prefiguraban a Cristo o a María, lo solían hacer de manera invertida. Asimismo, en este relato la inversión al mismo tiempo permite explicitar más didácticamente la diferencia que, incluso en las semejanzas ocasionales, se sigue manteniendo entre el pecador y la divinidad.

En conclusión, hemos recabado una considerable cantidad de elementos que Berceo incorpora respecto de la fuente latina para configurar la escena del milagro de la abadesa en relación a la de la anunciación y la natividad con el fin de relacionar su figura con la de la Virgen: sería ésta una anunciación invertida, en la que a través del anuncio no se concibe felizmente ("sin embargo") sino que se la libera de la aflicción o "embargo" de un embarazo. A través de estos recursos, el milagro se construye como perfecto tipo invertido de la concepción y parto del Mesías, luego del cual es restituida simbólicamente la virginidad de la abadesa, se restaura la legitimidad de su autoridad y se construye al niño-obispo como una paradigmática postfigura de Cristo.

En esta configuración tipológica Berceo se sirve no sólo de elementos que extrae de los (breves) pasajes de la anunciación y la natividad de los Evangelios canónicos, sino también de motivos procedentes de los relatos apócrifos. Ahora bien, García López (2008: 55) señala que Berceo utiliza motivos apócrifos "directamente o a través de lo que parece uso de una fuente común cercana a la Leyenda áurea". De hecho, como advierte Castro (2008: 208), las narraciones apócrifas tuvieron tal extraordinario éxito en los siglos XI y XII, que

[A] partir del siglo XII comenzaron a realizarse en Europa numerosas traducciones en vernáculo de los textos apócrifos, así como a confeccionarse compilaciones latinas de carácter edificante, que alcanzaron una gran difusión porque se reunían en ellas relatos apócrifos que resultaban realmente atractivos para estimular la piedad popular. A esta categoría pertenecen, jun- 
to con sus correspondientes traducciones vernáculas, el Speculum ecclesiae de Honorio de Autun (primera mitad del s. XII), la Historia scholastica de Pedro Coméstor (ca. 1160) el Speculum Historiale de Vicente de Beauvais (1264) y sobre todo la Legenda aurea de Jacobo de Vorágine (redactada hacia 1264).

Aunque no se pueda descartar, por tanto, la utilización de alguna fuente intermedia, lo cierto es que en los pasajes correspondientes a la anunciación o la natividad de los textos a los que Berceo tal vez tuvo acceso y hemos podido consultar, no siempre aparecen motivos apócrifos y, de aparecer, se menciona uno u otro de manera aislada, y no funcionando como constelación, tal como lo hacen en las fuentes apócrifas y en las escenas de Berceo ${ }^{32}$. Además, en la mayoría de los casos, estos motivos aparecen en el devenir de argumentaciones doctrinales o teológicas y no reelaborados en una narración ${ }^{33}$. Aunque sea un

32 Tanto en el Speculum Ecclesiae de Honorio de Autun como en la Storia Scholastica de Pedro Coméstor se reelaboran someramente ambas escenas. En el primer caso, tenemos el apartado "In annuntatione Sancta Mariae", donde se comentan las palabras del ángel sin referir ninguna otra circunstancia externa (PL 172, 903BC) y, ya al final de todo el escrito $(905 \mathrm{~b})$, se refiere a la virginidad pre y posparto y al parto sin dolor, aunque de manera teórica. Asimismo, en "De nativitate Domine" (PL 172, 0817C) se relata brevemente el nacimiento y se menciona el parto sin dolor y otros dos motivos apócrifos: el buey y el asno y el óleo emergente de las fuentes. Algo similar sucede en la Storia Scholastica: el episodio de la anunciación es narrado de manera muy lacónica siguiendo el texto canónico (cap. II., De conceptione Salvatoris PL 198, 1537C), mientras que en el episodio de la natividad (cap. V, De nativitate Salvatoris, PL 198, 1540A) el único motivo apócrifo presente son los dos animales. En ninguno de los dos casos aparece el episodio de las matronas.

33 De la tradición mariológica doctrinal (véase al respecto García de la Concha, 1978 y Menéndez Peláez, 1981) hemos consultado, primero, a Bernardo de Claraval (1090-1153). El único motivo que aparece en sus textos, que se repite tanto en el Sermo III In nativitate Domini (PL 183, 0122D) como en el In vigilia nativitatis Domini (PL 183, 0087C), es el parto sin dolor, conectado estrechamente a la virginidad ante y post-parto ("Siquidem et puer qui nascitur, Deus est; et mater de qua nascitur, virgo est; et partus ipse sine dolore est", PL 183, 0122D). Lo mismo sucederá en las Orationes de Anselmo de Canterbury (1033-1109): “Tu autem, domina mater eius, virgo in partu, virgo ante partum, et virgo post partum (...) dedit per te sine dolore parturientem", PL 158, 0942D y 0963D). En este caso, además, se alaba a la Virgen haciendo mención a sus pechos que amamantaron a Cristo ("Beata ubera tua, quae lactaverunt Christum Dominum", PL 158, 0963D). También Paschasio Radberto (785-860) en De Partu Virginis menciona el motivo del amamantamiento de Cristo ("tamen de carne Virginis procreatus est, et ideo uberibus iure lactatus commemoratur", PL 120, 1374C) y el del parto sin dolor ("Virgines quidem, ut sciamus quid sit integritas carnis et sanguinis; coniugatas vero, si est ulla corruptio in partu aut dolor", PL 120, 1375B y PL 120, 1374C). Hemos consultado también Ildefonso de Toledo (607-667), sobre todo el De perpetua virginitate $S$. Mariae, donde abandera la virginidad ante y post-partum, pero en este caso no se menciona el parto sin dolor ("cum conceptu virgo, per conceptum virgo, in conceptu virgo, post conceptum virgo; per partum virgo, cum partu virgo, post partum virgo", PL 96, 0060B). Respecto de la anunciación, sólo comenta el pasaje evangélico (PL 96, 0089B). Lo mismo sucederá con Pedro Damián (1007-1072) en su Carmina sacra et preces (PL 145, 0925A). 
texto posterior a los Milagros, la Legenda Aurea (Vorágine, 1982 [1267]) es, de hecho, el que presenta más características de relato en dichos pasajes, pues mientras avanza a través de argumentaciones, ejemplifica con breves raccontos. Acaso sea por este motivo que García López señale que Berceo tal vez maneje una fuente común.

Veamos este caso un poco más en detalle. Por un lado, la escena de la anunciación no es más que una commento del pasaje bíblico de Lucas (cap. LI, pp. 211-214), carente de motivo apócrifo alguno. Por el otro, en la de la natividad (cap. VI, pp. 54-55), más allá de algunos motivos no presentes en el milagro XXI (como el del buey y el asno) sí se relata el episodio de las comadronas (con otros nombres Zebel y Salomé), aunque muy someramente: se omiten los diálogos, la referencia a la leche, y también el parto sin dolor. En cambio, la cantidad de elementos comunes entre el texto de Berceo y los relatos apócrifos de la natividad inducirían a suponer, desde nuestra perspectiva, una reelaboración de la fuente bastante directa. Destaquemos, además, que en los apócrifos de la natividad las escenas de la anunciación y la natividad se encuentran contiguas, en el devenir de unos pocos folios. En efecto, resulta un detalle sumamente interesante el hecho de que el manuscrito de los milagros marianos latinos que, según Baños Vallejo (2011: XLVI), es el que transmite la copia más próxima a la fuente que posiblemente utilizó Berceo, transmita en sus primeros folios el De Nativitate Mariae ${ }^{34}$. Este manuscrito misceláneo prueba que los milagros marianos y los relatos apócrifos sobre la vida de María compartían el mismo contexto de circulación y lectura. Es, por tanto, altamente probable que Berceo haya tenido un conocimiento directo de ellos.

A su vez, dijimos que los apócrifos estaban sumamente difundidos, no sólo gracias a las compilaciones latinas edificantes, a los himnógrafos y a los defensores de la virginidad mariana, sino sobre todo gracias a la tradición popular, donde fueron infiltrándose "como corriente subterránea", según Santos Otero (2006: 118). Aunque nos inclinamos a suponer que Berceo tuvo acceso directo a alguno de estos relatos apócrifos, no puede desecharse la posibilidad de que en sus textos simplemente evidencie la influencia de la tradición popular. En este sentido, Castro (2008: 209) señala que "la penetración de elementos apócrifos fue tan grande que muchos autores no distinguen en modo alguno entre este tipo de narraciones y las canónicas". No creemos, sin embargo, que sea este el caso de Berceo, que en tantos otros textos demuestra su "objetividad

${ }^{34}$ Carrera de la Red (2000: 55) describe este manuscrito así: "el Ms. 110 de la Biblioteca Nacional de Madrid es un Códice misceláneo del s. XIII, compuesto por 239 folios. Contiene el Evangelio apócrifo del Nacimiento de María (fols.1r-7v); 47 milagros de la Virgen anónimos (fols. 7v-81v); el Libellus de miraculis beatae Mariae de Hugo Farsito (...) (fols. 81v-114v); y una copia incompleta de las partes I y II del Liber sancti Iacobi, tal como lo transmite el Codex Calixtinus (fols. 115r-238v)". 
escriturística" - la misma que lleva a García de la Concha a considerar espurias las coplas de los Loores de contenido apócrifo (vid. nota 6) - basada en un conocimiento profundo del texto bíblico. Al contrario, desde nuestra perspectiva, sea a través de fuentes manuscritas o sirviéndose de las leyendas populares, realiza un uso consciente de la tradición apócrifa. En efecto, es este particular manejo de las fuentes el que en este milagro sostiene la construcción tipológica de manera perfectamente engranada y el que facilita, a la vez, que el mensaje sea captado por el estrato popular. En otras palabras: la utilización de fuentes tanto canónicas como apócrifas no es más que otro ejemplo del cruce constantemente presente en la obra de Berceo entre teología y religiosidad popular.

\section{BIBLIOGRAFÍA}

Alonso, Martín (1986): Diccionario Medieval Español. Desde las Glosas Emilianenses hasta el s. $X V, 2$ ts., Salamanca, Pontificia Universidad de Salamanca.

Arcangeli Marenzi, María Laura (1968): Aspetti del tema della Vergine nella letteratura francese del Medioevo, Venezia, Libreria Universitaria Editrice.

Auerbach, Erich (1998): Figura. Sacrae Scripturae Sermo humilis, Madrid, Trotta, pp. 41-130.

Baños Vallejo, Fernando (ed.) (1997): Gonzalo de Berceo, Milagros de Nuestra Señora, Barcelona, Crítica.

Baños Vallejo, Fernando (ed.) (2011): Gonzalo de Berceo, Milagros de Nuestra Señora, Barcelona, Galaxia Gutenberg/Círculo de Lectores.

Bargaglio, Giuseppe (1982): Nuevo Diccionario de Teología. I. A. Testamento-Mariología, Madrid, Ediciones Cristiandad.

Bayo, Juan Carlos (2005): "La alegoría en el prólogo de los «Milagros de Nuestra Señora» de Gonzalo de Berceo", en Rebeca Sanmartín Bastida y Rosa Vidal Doval (coords.), La Metamorfosis de la alegoría: discurso y sociedad en la Península Ibérica desde la Edad Media hasta la Edad Contemporánea, Madrid/Frankfurt, Iberoamericana/Vervuert, pp. 51-70.

Bayo, Juan Carlos e Ian Michael (eds.) (2006): Gonzalo de Berceo, Los Milagros de Nuestra Señora, Madrid, Castalia.

Benito-Vessels, Carmen (2003): "Gonzalo de Berceo, el sacristán fornicario, la abadesa encinta y las Dueñas de Zamora”, Revista de Poética Medieval, 10, pp. 11-24.

Blaise, Albert (1954): Dictionnaire Latin-Français des Auteres Chrétiens, Turnhout, Brepols.

Boreland, Helen (1983): “Typology in Berceo's Milagros: the Judiezno and the Abadesa Preñada", Bulletin of Hispanic Studies, LX, pp. 15-29.

Bozoky, Edina (1984): “Les apocryphes bibliques”, en Pierre Riché y Guy Lobrichon (dirs.), Le Moyen Age et la Bible, Paris, Beauchesne, pp. 429-448.

Brea, Mercedes (2004-2005): "Tradiciones que confluyen en las Cantigas de Santa María", Alcanate, IV, pp. 269-289.

Carrera de la Red, Avelina y Fátima Carrera de la Red (2000): Miracula Beate Marie Virginis (Ms. Thott 128 de Copenhague). Una fuente paralela a los Milagros de Nuestra Señora de Gonzalo de Berceo, Logroño, Instituto de Estudios Riojanos, <http:/www.vallenajerilla.com/ berceo/carreradelared/milagrosthot $128 . \mathrm{htm}>$.

Castro, Eva (2008): "La Biblia y el universo dramático medieval", en M. Isabel Toro Pascua (coord.), La Biblia en la Literatura Española. I. Edad Media: El imaginario y sus géneros, Madrid, Editorial Trotta, pp. 191-220. 
Cea Gutiérrez, Antonio (2001): "El cielo como triunfo: Los galardones de la palma y la corona en Gonzalo de Berceo", Revista de dialectología y Tradiciones Populares, LVI, 2, pp. 5-32.

Chaves, Maite y Teresa Labarta de Chaves (1978): "Influencia de las artes visuales en la caracterización de la Virgen en Los Milagros de Nuestra Señora", Berceo, 94-95, pp. 89-96.

Colunga, Alberto y Laurentio Turrado (1951): Biblia Sacra Iuxta Vulgatam Clementinam, Madrid, Biblioteca de Autores Cristianos.

De Lubac, Henri (1959): Exégèse médiévale: les quatre sens de l'Écriture, première Partie, t. I et II, Paris, Aubier.

Devoto, Daniel (1974): "Pisó yerba enconada", en Daniel Devoto, Textos y contextos. Estudios sobre la tradición, Madrid, Gredos, pp. 11-46.

Deyermond, Alan (1978): "La estructura tipológica del Sacrificio de la Misa”, Berceo, 94-95, pp. 97-104.

Deyermond, Alan (1981): "Observaciones sobre las técnicas literarias de los Loores de Nuestra Señora”, en Emilio Alarcos Llorach (ed.), Actas de las III Jornadas de Estudios Berceanos, Logroño, Instituto de Estudios Riojanos, pp. 57-62.

Díaz Tena, María Eugenia (2010): "La infancia de Jesús en la literatura medieval castellana", Via Spiritus, Revista de História da Espiritualidade e do Sentimento Religioso, 17, pp. 9-45.

Disalvo, Santiago (2013): Los monjes de la Virgen: representación y reelaboración de la cultura monacal en las Cantigas de Santa María de Alfonso X, Newark, Juan de la Cuesta.

Diz, Ana (1995): Historias de certidumbre: los Milagros de Berceo, Newark, Juan de la Cuesta.

Domínguez Rodríguez, Ana (1984): "Imágenes de la mujer en las Cantigas de Santa María", en La imagen de la mujer en el arte español, Madrid, Universidad Autónoma de Madrid, pp. 2942.

Dutton, Brian (ed.) (1971): Gonzalo de Berceo, Los Milagros de Nuestra Señora. Obras Completas II, London, Tamesis.

Fidalgo, Elvira (1995): "La abadesa preñada (Berceo, 21). Seis versiones románicas y tres en latín”, en Juan Paredes Núñez (ed.), Medioevo y literatura. Actas del V Congreso de la Asociación Hispánica de Literatura Medieval, Granada, Universidad de Granada, II, pp. 329-344.

Foster, David (1970): Christian Allegory in Early Hispanic Poetry, Kentucky, University Press of Kentucky.

García de la Concha, Víctor (1978): "Los Loores de Nuestra Señora, un «Compendium Historiae Salutis»", Berceo, 94-95, pp. 133-189

García de la Concha, Víctor (1992): "La mariología en Berceo", en Gonzalo de Berceo, Obras Completas, Isabel Uría (coord.), Madrid, Espasa Calpe, pp. 61-87.

García López, Jorge (2008): "La Biblia en la cuadernavía del siglo XIII", en M. ${ }^{a}$ Isabel Toro Pascua (coord.), La Biblia en la Literatura Española. I. Edad Media: El imaginario y sus géneros, Madrid, Editorial Trotta, pp. 35-68.

García Turza, Claudio (ed.) (1992): Gonzalo de Berceo, Los Milagros de Nuestra Señora, en Gonzalo de Berceo, Obras Completas, Isabel Uría (coord.), Madrid, Espasa Calpe.

Garci-Gómez, Miguel (1989): "La abadesa embarazada por el pie", Revista de Dialectología y Tradiciones Populares, 44, pp. 7-26.

Gerli, Michael (1985): "La tipología bíblica y la introducción a los Milagros de Nuestra Señora", Bulletin of Hispanic Studies, 62, pp. 7-14.

Gerli, Michael (ed.) (1989): Gonzalo de Berceo, Milagros de Nuestra Señora, Madrid, Cátedra.

Giles, Ryan (2013): "Sewn without a Needle: The Chasuble of St. Ildephonsus in the Milagros de Nuestra Señora", La corónica, 42.1, pp. 281-97.

González, Javier (2010): "La alegoría cristiana o in factis en el prólogo de los Milagros de Nuestra Señora de Berceo", Revista de Literatura Medieval, XXII, pp. 105-154.

Goode, Teresa (1933): Gonzalo de Berceo, El Sacrificio de la Misa: a Study of its Symbolism and of its Sources, Washington, Catholic University of America. 
Hamlin, Cinthia M. (2015): "«Sobre yelo escribes»: el protagonismo de lo escrito (y otras lecturas metapoéticas) en los milagros «La casulla de San Ildefonso» y «Teófilo» de Berceo", Incipit, XXV, pp. 71-102.

Marenzi, Arcangeli (1968): Aspetti del tema della vergine nella letteratura francese del medioevo, Venezia, Libreria Universitaria.

Menéndez Peláez, Jesús (1981): "La tradición mariológica en Berceo", en Actas de las III Jornadas de Estudios Berceano, Logroño, Instituto de Estudios Berceanos, pp. 113-128.

Migne, Jacques-Paul (ed.) (1844-1855): Patrología cursus completus. Series Latinas, 221 vols., Paris, Migne.

Orduna, Germán (1967): "La introducción a los Milagros de Nuestra Señora de Berceo. El análisis estructural aplicado a la comprensión de la intencionalidad de un texto literario", en Actas del Segundo Congreso de la Asociación Internacional de Hispanistas (Nimega, 1965), Nimega, Instituto Español de la Universidad de Nimega, pp. 447-456.

Salvador Miguel, Nicasio (ed.) (1992): Gonzalo de Berceo, Loores de Nuestra Señora, en Gonzalo de Berceo, Obras Completas, Isabel Uría (coord.), Madrid, Espasa Calpe, pp. 861-930.

Santos Otero, Aurelio (ed.) (2006): Los Evangelios Apócrifos, edición bilingüe, Madrid, Biblioteca de Autores Cristianos.

Snow, Joseph (1982): "Gonzalo de Berceo and the Miracle of Saint Ildefonso: Portrait of the Medieval Artist at Work", Hispania, 65.1, pp. 1-11.

Strubel, Armand (1975): “«Allegoria in factis» et «Allegoria in verbis»”, Poétique, 23, pp. 342357.

Vázquez-Ayora, Gerardo (1997): Introducción a la traductología, Washington, Georgetown University Press.

Victorin de Poetovio (1997): L'apocalypse et autres écrits, Paris, Éditions du Cerf.

Vorágine, Santiago de (1982 [1267]): La leyenda dorada, 1, Fray José Manuel Macías (trad.), Madrid, Alianza Editorial.

Woollcombe, Kenneth (1957): "The Biblical Origins and Patristic Development of Typology", en Geoffrey Lampe y Kenneth Woollcombe (eds.), Essays on Typology, London, SCM Press.

Fecha de recepción: 20 de septiembre de 2016

Fecha de aceptación: 23 de enero de 2017 